\title{
The Use of Iron Ore Tailings in the Iron Quadrangle of Minas Gerais, Brazil
}

\section{Moacyr Rodrigues ${ }^{1}$, Jordanna Vogt ${ }^{2}$, Lílian Lima$^{1}$, Glaucia Duarte ${ }^{1}$, Carolina Freire ${ }^{1}$, and Fernando Lameiras ${ }^{1}$}

${ }^{1}$ Nuclear Technology Development Center, 31270-901 Belo Horizonte, Minas Gerais, Brazil

${ }^{2}$ Vale S. A., Mina de Águas Claras, 34000-000 Nova Lima, Minas Gerais, Brazil

\section{Abstract}

The Iron Quadrangle of Minas Gerais comprises 7,000 km ${ }^{2}$ and accounts for about $60 \%$ of Brazil's iron ore production. The rocks explored in this region are banded iron formations. The processing of this rock to produce the iron ore concentrate generates large quantities of tailings that were being stored in dams. After the ruptures of the dams in 2015 (Mariana-MG) and 2019 (Brumadinho-MG), dam storage became very difficult. Other storage destinations for tailings are now being considered, including dry storage in piles and the use of tailings as a raw material for other manufacturing chains, such as civil construction and road paving. Due to the fine particle size of the

Corresponding Author: Fernando Lameiras fsl@cdtn.br

Received: 20 March 2020 Accepted: 30 April 2020 Published: 13 April 2020

Publishing services provided by Knowledge E

(c) Moacyr Rodrigues et al. This article is distributed under the terms of the

Attribution License, which permits unrestricted use and redistribution provided that the original author and source are credited.

Selection and Peer-review under the responsibility of the RICON19 - REMINE International Conference Conference Committee.

\section{G OPEN ACCESS} tailings, the use of Portland cement to manufacture products for civil construction is limited. However, alkali activated cements should play an important role, due to their ability to incorporate fine grained materials. Although alkali activated mortars made with the tailings have good characteristics, their cost is very high, especially when sodium silicate prices are elevated. In this study, sodium silicate synthesis from the tailings, alternative calcined clays, the use of the overburden and other aluminosilicate sources are being investigated with a view to reducing the manufacturing cost.

Keywords: Iron ore tailings, Alkali-activated, Building Materials

\section{Introduction}

Iron ore concentrate is an important product of Brazil exported to many countries, especially China. The Iron ore Quadrangle of Minas Gerais produces about 60\% of the iron ore in Brazil. Banded iron formations are exploited in this region. It is estimated that for each ton of iron ore concentrate produced, one ton of tailings is generated, which means a generation of 400,000 tons per day [1]. These tailings were usually stocked in dams. But after the ruptures of Fundão Dam in Mariana city in 2015 and of Córrego do Feijão Dam in Brumadinho city in 2019, both in the Iron Quadrangle, the storage of tailings in dams became unsustainable. Other destinations for the tailings are being considered, such as storage in piles and their use as raw materials for other manufacturing chains. Products for civil construction should play an important 
role because they can use large amounts of tailings. Due to the fine granulometry, the use of the tailings as fine aggregate in Portland cement concrete is limited (Figure 1).

One observes that alkali activated mortars with the tailings as fine aggregated can develop good mechanical properties for use as non-structural concrete. One of the authors (Glaucia Duarte) obtained compression strengths of up to $43 \mathrm{MPa}$ for samples of mortars made with metakaolin, sodium silicate, sodium hydroxide and addition of 40$60 w t \%$ of the tailings sedimented in the Candonga dam after the Fundão dam rupture.

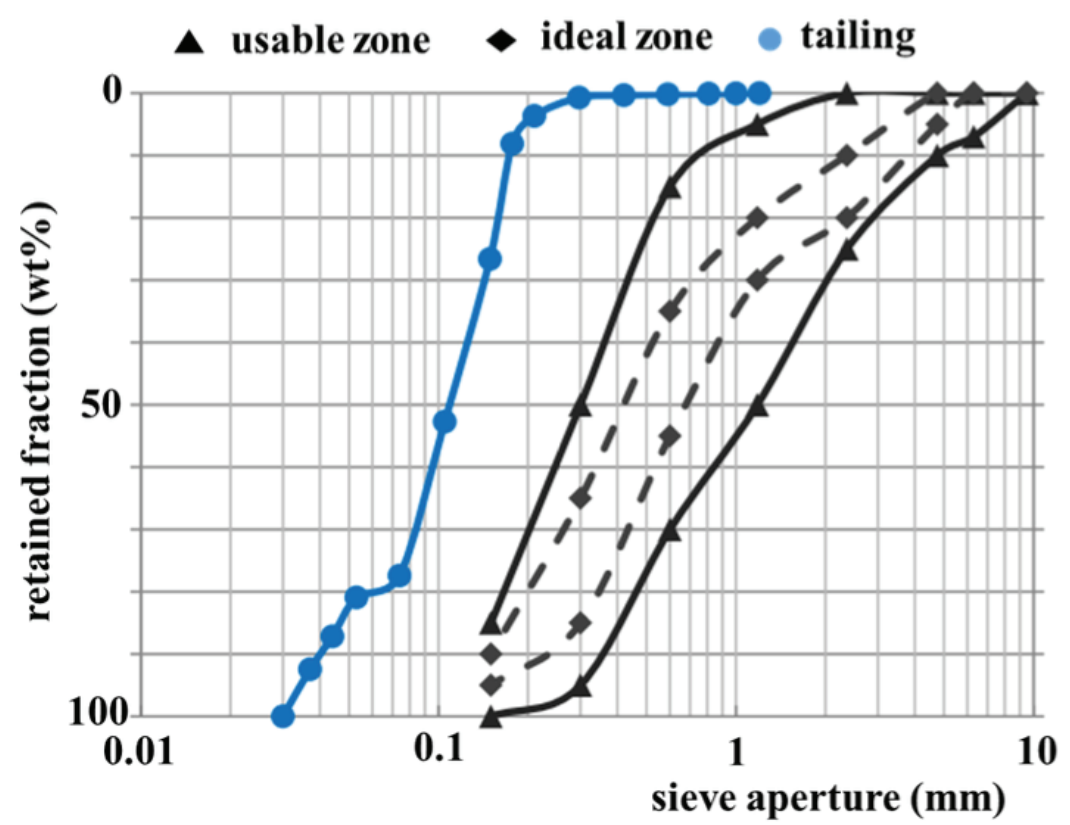

Figure 1: Comparison of the granulometry distribution of the tailing from iron ore with the requirements for fine aggregate according to the Brazilian standard NBR 7211 [2].

But the estimated prices of the alkali activated concretes is at least three times higher than the Portland cement concrete, as shown in Figure 2 . The sodium silicate is by far the most important raw material concerning the cost, followed by sodium hydroxide. The objective of this research is to obtain alkali activated mortars with incorporation of iron ore processing tailings to manufacture non-structural concrete products for civil construction with competitive prices in the Brazilian market.

The tailings are rich in quartz. Sodium hydroxide is routinely used in the iron ore concentration process in large amounts, such that the iron ore mining companies usually have a well established supply chain for this raw material. The tailings and the sodium hydroxide may be used to obtain sodium silicate. Also, the overburden that is removed to exploit the iron ore is rich in clays, such as kaolin and muscovite (phyllite [4]). Once calcined and combined with sodium silicate obtained from the tailings as above, it can 

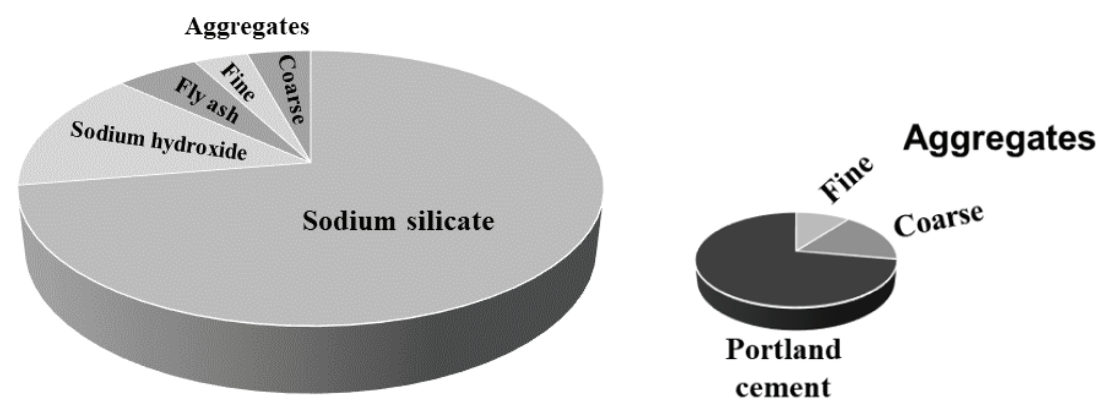

Figure 2: Comparison of prices of alkali activated concrete and Portland cement concrete (US prices, adapted from Tempest et al. [3])

be used to obtain an alkali activated cement. A mortar can be obtained with the addition of tailings to this alkali activated cement.

\section{Materials and Methods}

Tailings from one concentration facility of Vale and Candonga dam were utilized. Vale samples were collected, dried and characterized by X-rays diffractometry and laser granulometry. The composition of this tailing is $80-90 w t \%$ of quartz and $10-20 w t \%$ of iron oxides and clays. As shown in Figure 1, this tailing is a very fine aggregate. Samples of Candonga were collected after dredging, dried and characterized as small aggregate according to Brazilian standards. The composition of Candonga tailing is $70-80 \%$ of quartz, $15-25 w t \%$ of iron oxides, clays and organic matter.

Technical grade flakes of sodium hydroxide were dissolved in tap water from the local water supplier to obtain a $30 \mathrm{M}$ solution, which is mixed with the tailing to obtain a uniform paste. This paste is heated in a muffle furnace for 4 hours at $450^{\circ} \mathrm{C}$ to obtain powdered solid sodium silicate. The sodium silicate was characterized by $\mathrm{X}$-rays diffractometry.

Technical quality kaolin was purchased from Sulfal (a local supplier of cosmetic and cleaning materials). The kaolin and overburden were calcined at $800^{\circ} \mathrm{C}$ for 4 hours. The obtained metakaolin and calcined overburden were characterized by X-rays diffractometry (DRX) and Fourier-transform infrared spectroscopy (FTIR).

Alkaline sodium silicate was also purchased on the local market (Getex, $\mathrm{SiO}_{2} / \mathrm{Na}_{2} \mathrm{O}=$ 2.12 , content of solids $\approx 45 w t \%)$. 


\subsection{Mortars with Candonga sediment}

$10 \mathrm{M}$ sodium hydroxide solution prepared with tap water and the alkaline sodium silicate were mixed to obtain the activation solution. Metakaolin was mixed with the activation solution in a proportion to give a Si/Al relation of 1.5 . The mixture was performed manually with a spatula up to produce an uniform paste. Then the tailing was added to the paste and mixed up to produce a uniform fresh mortar. The fresh mortar was set in cylindrical moulds (10 cm-diameter; $20 \mathrm{~cm}$-height) and then stirred in an orbital stirrer to remove air bubbles. The hardening was performed at room conditions and at $60^{\circ} \mathrm{C}$ in an oven, both for 24 hours. After demoulding, the samples were let to cure for 7 and 28 days at room conditions.

A $2^{3}$ factorial design was performed as shown in Table 1. The responses were the compressive strength and water absorption of the cured samples. Three samples of each combination of the factors were characterized. The compressive strength was measured according to the Brazilian norm ABNT NBR 7215. The water absorption was measured according to the Brazilian norm ABNT NBR 9778.

TABLE 1: $2^{3}$ factorial design for samples of alkali activated mortar with the sediment of Candonga.

\begin{tabular}{l|c|c|}
\hline Factor & Low level code: $\mathbf{- 1}$ & High level code: $\mathbf{+ 1}$ \\
\hline Tailing content & $40 w t \%$ & $60 w t \%$ \\
\hline Hardening & Room conditions 24 hours & $60^{\circ} \mathrm{C} 24$ hours \\
\hline Curing & 7 days & 28 days \\
\hline
\end{tabular}

\subsection{Mortars with solid powered sodium silicate and tailings}

A uniform mixture of $62 \mathrm{wt} \%$ of metakaolin and $38 \mathrm{wt} \%$ of solid powdered sodium silicate was manually prepared with a spatula. In the following, dried tailing was added and mixed to obtain a uniform powder. Two additions of tailings were studied: $79 w t \%$ and $128 \mathrm{wt} \%$ in relation to the mass of metakaolin plus powdered sodium silicate. Tap water was added to the powder and mixed with a spatula to obtain a uniform and workable paste [5]. Much heat is released in this process, such that water should be added slowly to keep the temperature below the boiling point of water. Two additions of water were studied: $54 \mathrm{wt} \%$ and $60 \mathrm{wt} \%$ in relation to the mass of metakaolin plus powdered sodium silicate. The fresh mortar was set in cylindrical moulds $(10 \mathrm{~cm}$ diameter, $20 \mathrm{~cm}$ height) and then stirred in an orbital stirrer to remove air bubbles. The hardening was performed 
at room temperature for 24 hours. After demolding, the samples were let to cure for 7 and 28 days.

A $2^{3}$ factorial design was performed as shown in Table 2 . The response was the compressive strength according to the Brazilian norm ABNT NBR 7215. Three samples of each combination of the factors were characterized.

TABLE 2: $2^{3}$ factorial design for the samples of alkali activated mortar samples made with powdered sodium silicate and tailings

Factor
Tailing content
Water addition
Curing

\begin{tabular}{|} 
Low level code: -1 \\
\hline $79 w t \%$ \\
\hline $54 w t \%$ \\
7 days
\end{tabular}

High level code: $\mathbf{+ 1}$
$\begin{gathered}128 w t \% \\ 60 w t \% \\ 28 \text { days }\end{gathered}$

\subsection{Alkali activation with the calcined overburden}

The alkali activation solution was prepared with $10 \mathrm{M}$ sodium hydroxide and alkaline silicate solutions. This activation solution was mixed with the calcined overburden in such a proportion according to the contents of metakaolin and metamoskovite. The obtained paste was poured into cylindrical moulds ( $5 \mathrm{~cm}$-diameter and $10 \mathrm{~cm}$-height), stirred to remove air bubbles and cured under room temperature for 24 hours. After hardening the samples were demoulded.

\section{Results and Discussion}

The Candonga tailing has $28 w t \%$ of powdered material, presence of organic material and a finer granulometry in relation to the tailing from the concentration plant. This was expected since flora and fauna of the riverbanks and riverbeds sediments were carried along the tailings after the collapse of Fundão dam. The powdered solid sodium silicate is composed mainly of $\mathrm{Na}_{2} \mathrm{SiO}_{3}$, with iron oxides and quartz as minority phases. Kaolin was fully transformed into metakaolin after calcination. The calcined overburden showed amorphous characteristics with quartz and rutile as minority phases.

\subsection{Mortars with Candonga tailing}

The results of compressive strength and water absorption of the Candonga mortar were analysed with the software Minitab. Figure 3 shows the response surface for 
the compressive strength. Hardening conditions influenced the shape of the response surface. The increase of the tailing addition produced samples with lower resistances. For hardening at $60^{\circ} \mathrm{C}$, the curing for 28 days produced samples with higher resistances. Compressive strengths between 19 and $43 \mathrm{MPa}$ were observed.

Figure 4 shows the response surface for the water absorption of the Candonga mortar. The hardening conditions have a strong influence on the shape of the surface. The water absorption is lower for the hardening at $60^{\circ} \mathrm{C}$ and decreases with the increase of the content of tailing and longer curing. Water absorptions between 19 and 41wt\% were observed.

These results indicate that Candonga mortar can be used for the production of pavers and other pieces for pedestrian sidewalks and street pavings. Concerning the use as laying mortars, the observed water absorptions are higher than the Brazilian standards.

\subsection{Mortars with solid powered sodium silicate and tailings}

Figure 5 shows the response surface of the compressive strength (CS) of the samples. There is no influence of the addition of tailings. It is an indication that more tailing may be added to the mortar. The strength increases with the curing time. A small increase on water addition (from $54 \mathrm{wt} \%$ to $60 \mathrm{wt} \%$ ) strongly decreases the compressive resistance. Water is necessary to promote the alkali activation reactions and to give workability to the mortar, but it should be added as little as possible.

\subsection{Alkali activation with the calcined overburden}

In this case, only the feasibility was demonstrated up to now. The samples showed neither cracks nor efflorescence after 30 days of curing at room temperature. The overburden is considered a promising raw material for alkali activation because it is available in large quantities within the mine area.

Alkali activation with the overburden and the solid powdered silicate obtained from the tailing, as shown in this paper, may also be considered for the stabilization of tailing piles.

\section{Acknowledments}

To INCT Midas, FAPEMIG, CAPES, CNPq and VALE S.A. 


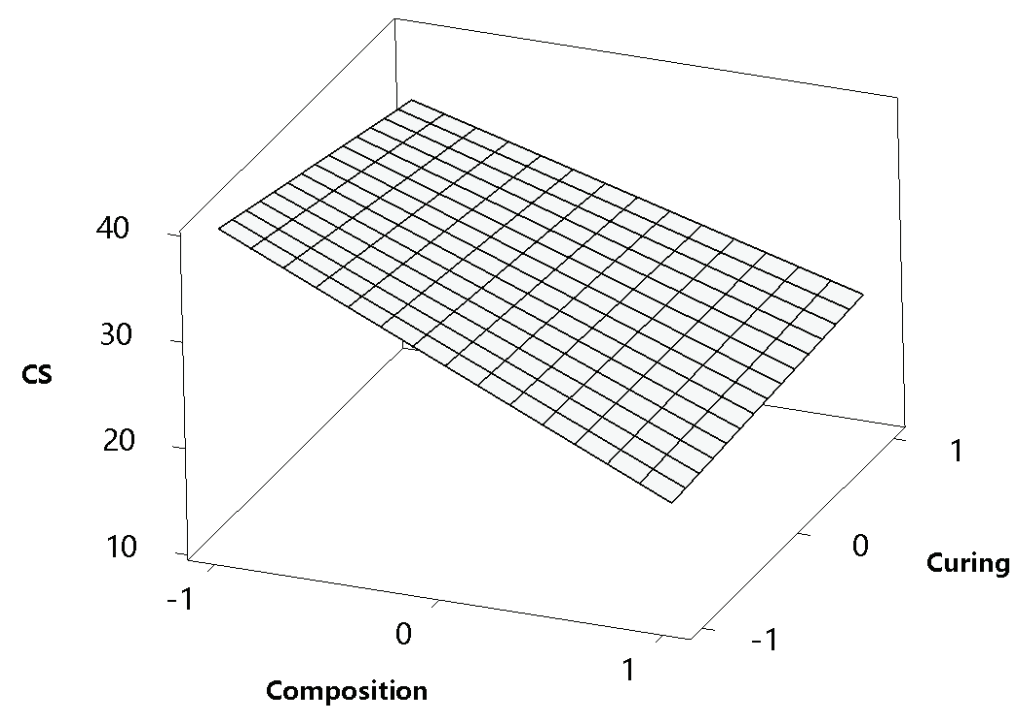

Hardening at room temperature, 24 hours

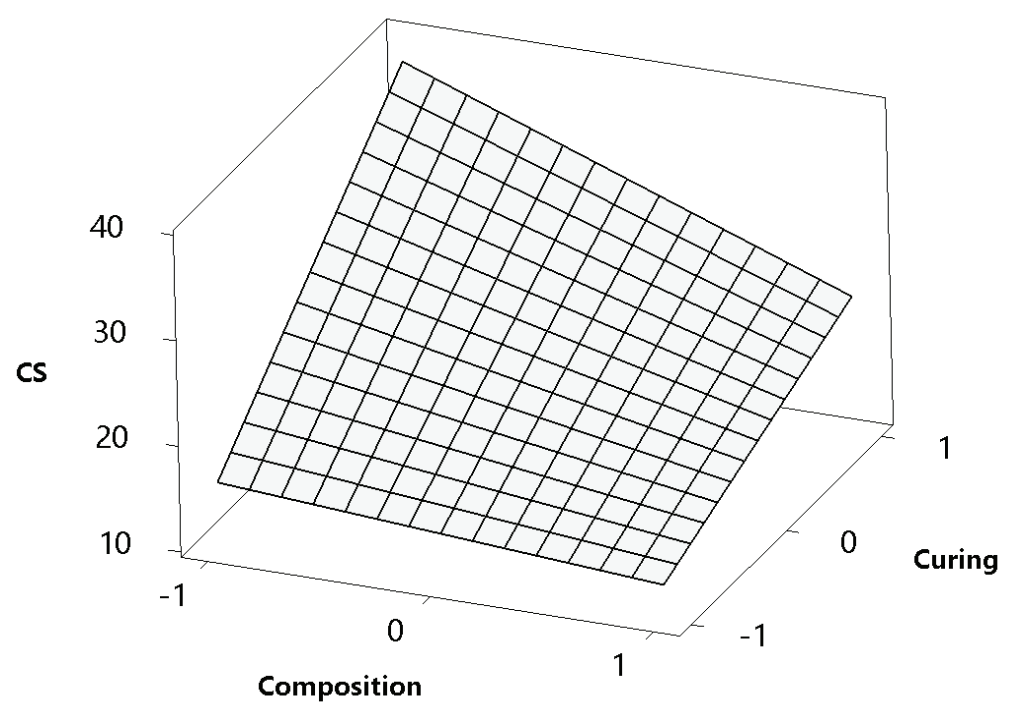

Hardening at $60^{\circ} \mathrm{C}, 24$ hours

Figure 3: Response surface of the compressive strength (CS, in MPa) of alkali activated mortars with the addition of $40 w t \%(-1)$ and 60 wt\% (-1) of tailing for 7 days (-1) and 28 days (+1) of curing and hardening at room temperature and at $60^{\circ} \mathrm{C}$.

\section{Conclusions}

Alkali activation materials can incorporate the finely granulated tailings from iron ore exploitation in the Iron Quadrangle of Minas Gerais-Brazil more efficiently than Portland cement. Solid powdered sodium silicate can be obtained from the tailing by reaction with sodium hydroxide, which is usually available at the iron mining facilities. One-part 


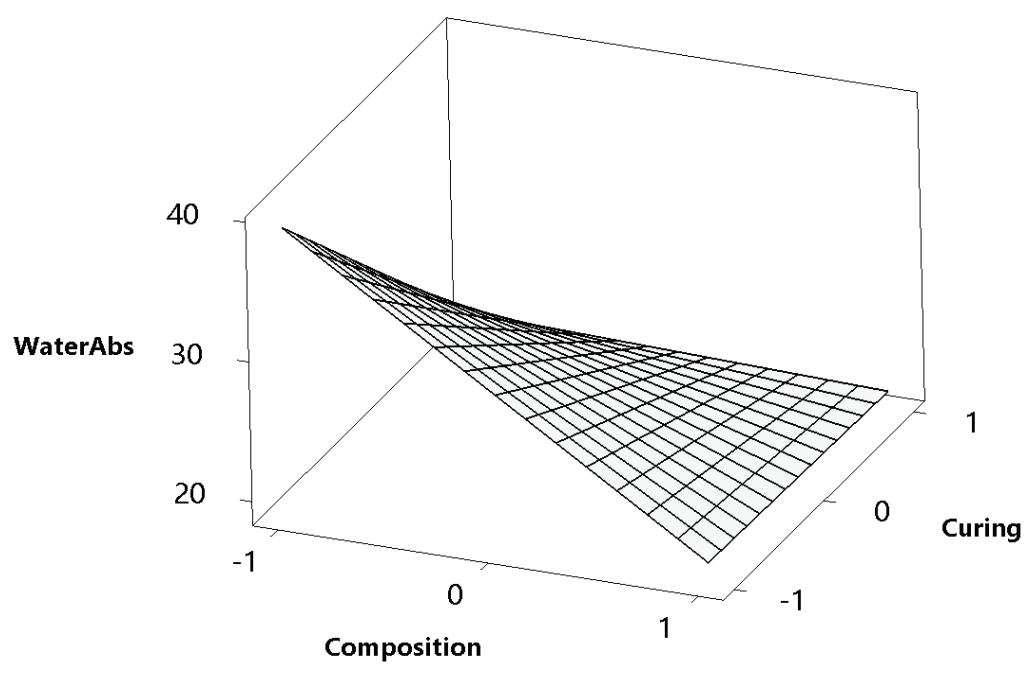

Hardening at room temperature, 24 hours

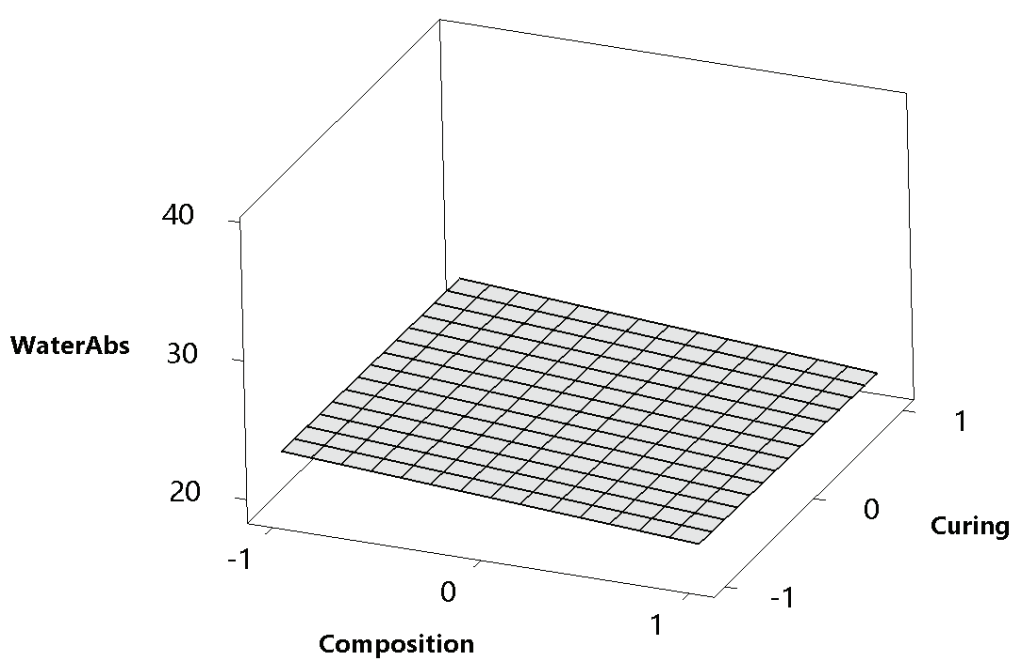

Hardening at $60^{\circ} \mathrm{C}, 24$ hours

Figure 4: Response surface of the absorption (WaterAbs, in wt\%) of alkali activated mortars with the addition of $40 w t \%(-1)$ and 60 wt\% (-1) of tailing for 7 days (-1) and 28 days (+1) of curing and hardening at room temperature and at $60^{\circ} \mathrm{C}$.

alkali activation with the incorporation of the tailings is feasible by the "just add water procedure". Mortars can be obtained by alkali activation and addition of tailings that can be used for manufacturing pavers for paving street and pedestrian sidewalks. The overburden is a potential raw material for alkali activation. 


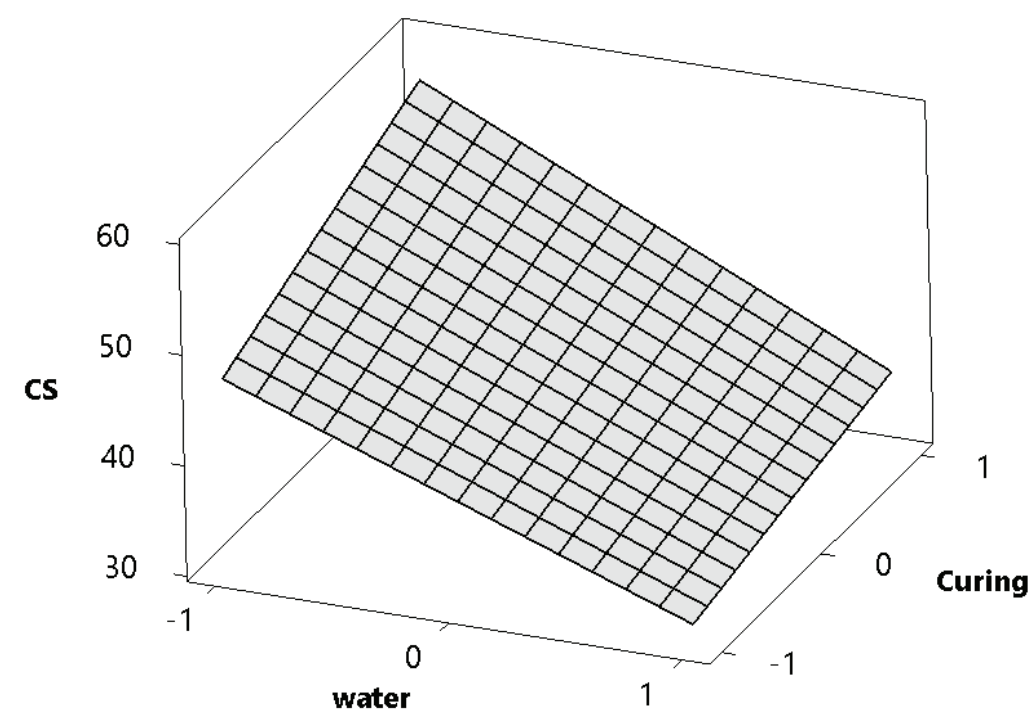

Tailing addition : $79 \mathrm{wt} \%$

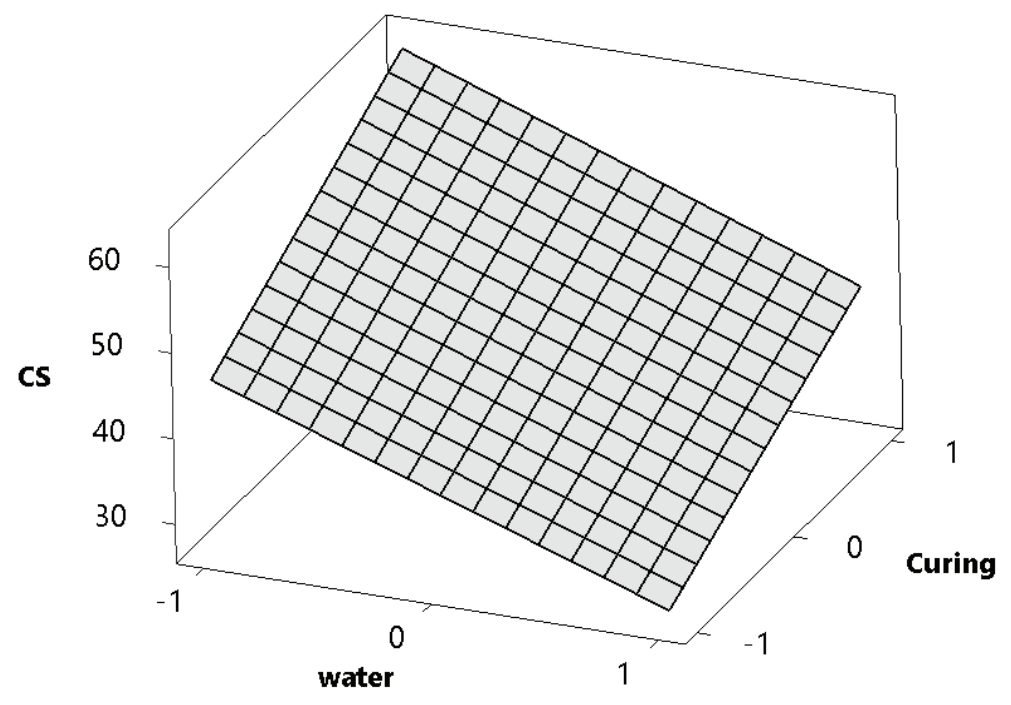

Tailing addition : $128 \mathrm{wt} \%$

Figure 5: Response surface of the compression strength (CS in MPa) of alkali activated mortars made with solid powdered sodium silicate with addition of $54 w t \%(-1)$ and $60 w t \%(+1)$ of water for 7 days and 28 days of curing.

\section{References}

[1] MTPA, Relatório (2018). Available at http://portaldamineracao.com.br/wp-content/ uploads/2018/05/relatorio_corredores_logisticos_minerio_v1-0-copia.pdf

[2] V. Melo, Dissertação (2012). REDEMAT - Universidade Federal de Ouro Preto. Available at https://www.repositorio.ufop.br/bitstream/123456789/2819/1/ DISSERTA\{\%\}c3\{\%]87\{\%\}c3\{\%\}830_\{\%\}20Utiliza\{\%\}c3\{\%\}a7\{\%\}c3\{\%\}a3oRes\{\%\}c3\{\%\}adduoGer 
PDF

[3] Tempest, B. et al. (2015). Manufacture of full-scale geopolymer cement concrete components: A case study to highlight opportunities and challenges. PCl Journal vol. 60 (6), p 39-50.

[4] Silva, K., Rabelo, A. and Fagury Neto. E. (2014). Desenvolvimento De Geopolímeros A Partir De Filito E Caulim Do Estado Do Pará 21o Cbecimat. Available at http: //www.metallum.com.br/21cbecimat/CD/PDF/105-004.pdf

[5] Luukonen, A., et al. (2018). One-part alkali-activated materials: A review, Cement and Concrete Research, vol. 103, p 21-34. 